\title{
Risk-Taking Behaviours In Relation To Attention Deficit And Hyperactivity Disorder In Iranian Male Workers: A Latent Class Analysis [Letter]
}

This article was published in the following Dove Press journal: Neuropsychiatric Disease and Treatment

\section{Olivia Knowles (D) \\ Ellen Richards}

Department of Medicine and Dentistry, Barts and the London School of Medicine and Dentistry, London, UK
Correspondence: Olivia Knowles Department of Medicine and Dentistry, Barts and the London School of Medicine and Dentistry, London, UK

Email o.e.g.knowles@smdI4.qmul.ac.uk

\section{Dear editor}

We read with interest the article by Abbasi-Ghahramanloo et al, shedding light on the relationship between risk-taking behaviours and attention deficit and hyperactivity disorder (ADHD) in Iranian workers. ${ }^{1}$ The study identified 4 latent classes from low to high-risk, finding that $6.6 \%$ of the workers showed behaviours related to moderate or high-risk classes. Conclusions drawn also stated that a diagnosis of ADHD increased the chance of falling into the moderate and high classes, consistent with the core symptoms of ADHD and exhibition of impulsivity, inattention and hyperactivity that go hand-in-hand with risk-taking behaviour. We thank the authors for adding to a growing pool of knowledge encompassing ADHD and the likelihood of partaking in risk-taking behaviours. Here, we would like to offer some opinions on the study.

The authors state in their methods section that ADHD was measured using the Conner's Adult ADHD Rating scales (CAARS) 30-item questionnaire, with a score of $>15$ considered to show ADHD. ${ }^{1}$ This scale was used to "diagnose" workers with ADHD, and conclusions were drawn based on this questionnaire, such as comparison of ADHD prevalence. Typically, CAARS is used as a screening tool for ADHD and is not validated for diagnostic purposes, ${ }^{2}$ nor does it encompass any form of recommended measure for diagnosis of ADHD.

Because of this, we feel that the data on the "prevalence" of ADHD in these Iranian workers cannot be compared to the other studies referenced looking at ADHD prevalence, for example, in prisoners. The latter paper used a clinical interview based on the DSM-V criteria for ADHD, and a psychiatric interview alongside an ADHD screening questionnaire. ${ }^{3}$ This method would be more in line with recommendations for diagnosing $\mathrm{ADHD}$, and therefore more reliable data to be compared to other studies. Additionally, a recent meta-analysis by Young et al showed that the prevalence of ADHD in jails is five to tenfold more than that of the general population, ${ }^{4}$ so it could be seen as imbalanced to compare the prevalence of ADHD in workers and prisoners.

The second study referenced looks at the presence of ADHD "symptoms" in university students, defined by CAARS, rather than diagnosis. ${ }^{5}$ This paper has more similarities to Abbasi-Ghahramanloo et al's methods section and therefore statistical comparison between the two papers is more appropriate. We would therefore urge future research to ensure there is clarification between formal diagnosis of ADHD and presence 
of ADHD symptoms when comparing statistics from previous studies and make this distinction clear in their methodology.

\section{Disclosure}

The authors report no conflicts of interest in this communication.

\section{References}

1. Abbasi-Ghahramanloo A, Janani L, Malakouti SK, Rabetian M, Rimaz S. Risk taking behaviors in relation to Attention Deficit and Hyperactivity Disorder in Iranian male workers: a latent class analysis. Neuropsychiatr Dis Treat. 2019;15:2513-2520. doi:10.2147/NDT.S221858
2. Ghassemi F, Moradi MH, Tehrani-Doost M, Abootalebi V. Evaluation of estimating missed answers in conners adult ADHD rating scale (screening version). Iran J Psychiatry. 2010;5(3): $108-112$.

3. Hamzeloo M, Mashhadi A, Salehi Fadardi J. The prevalence of ADHD and comorbid disorders in Iranian adult male prison inmates. $J$ Atten Disord. 2016;20(7):590-598. doi:10.1177/ 1087054712457991

4. Young S, Moss D, Sedgwick O, Fridman M, Hodgkins P. A metaanalysis of the prevalence of attention deficit hyperactivity disorder in incarcerated populations. Psychol Med. 2015;45(2):247-258. doi: $10.1017 / \mathrm{S} 0033291715001269$

5. Mosalanejad M, Mosalanejad L, Lashkarpour K. Prevalence of ADHD among students of Zahedan University of Medical Science in Iran. Iran J Psychiatry Behav Sci. 2013;7(2):83-90.

Dove Medical Press encourages responsible, free and frank academic debate. The content of the Neuropsychiatric Disease and Treatment 'letters to the editor' section does not necessarily represent the views of Dove Medical Press, its officers, agents, employees, related entities or the Neuropsychiatric Disease and Treatment editors. While all reasonable steps have been taken to confirm the content of each letter, Dove Medical Press accepts no liability in respect of the content of any letter, nor is it responsible for the content and accuracy of any letter to the editor.

\section{Publish your work in this journal}

Neuropsychiatric Disease and Treatment is an international, peerreviewed journal of clinical therapeutics and pharmacology focusing on concise rapid reporting of clinical or pre-clinical studies on a range of neuropsychiatric and neurological disorders. This journal is indexed on PubMed Central, the 'PsycINFO' database and CAS, and is the official journal of The International Neuropsychiatric Association (INA). The manuscript management system is completely online and includes a very quick and fair peer-review system, which is all easy to use. Visit http://www.dovepress.com/testimonials.php to read real quotes from published authors. 